\title{
Quantification of Atmospheric Emissions and Energy Metrics from Simulated Clamp Kiln Technology in the Clay Brick Industry
}

\author{
Oladapo Akinshipe* and Gerrit Kornelius
}

\author{
Environmental Engineering Group, Chemical Engineering, University of Pretoria (oladapoak@gmail.com)
}

\begin{abstract}
The quantification of atmospheric emissions from clamp kilns in the clay brick industry has met with limited success globally. The complex configuration of clamp kilns using coal or other carbonaceous fuels and uncertainties regarding kiln combustion conditions, has proven to be a hurdle in measurement of emissions and standardization of process and energy metrics. To enable quantification of these metrics, a model kiln was designed to simulate operating conditions and configuration similar to transverse slice of a typical full-scale clamp kiln, but with lower capacity (20,000 to 35,000 bricks per cycle). Hourly measurements of flue gas at extraction duct were recorded for thirteen firing cycles obtained from various source factories, each lasting $8-14$ days, for $\mathrm{SO}_{2}, \mathrm{NO}_{2}, \mathrm{NO}, \mathrm{PM}, \mathrm{CO}$ and $\mathrm{CO}_{2}$ emissions in the extraction stack. A statistical mean efficiency for model kiln emissions capturing and channelling capacity was calculated from sulfur mass balance results of batches that lie within $95 \%$ confidence interval of assumed true mean $(100 \%)$ to give $84.2 \%$. Final emission factors (mean \pm standard deviation) were quantified as $22.5 \pm 18.8 \mathrm{~g} / \mathrm{brick}$ for $\mathrm{CO}, 0.14 \pm 0.1 \mathrm{~g} / \mathrm{brick}$ for $\mathrm{NO}, 0.0 \mathrm{~g} / \mathrm{brick}$ for $\mathrm{NO}_{2}, 0.14 \pm 0.1 \mathrm{~g} /$ brick for $\mathrm{NO}_{2}, 1.07 \pm 0.7 \mathrm{~g} / \mathrm{brick}$ for $\mathrm{SO}_{2}, 378 \pm 223 \mathrm{~g} / \mathrm{brick}$ for $\mathrm{CO}_{2} ; 0.96 \pm 0.5 \mathrm{~g} / \mathrm{brick}$ for $\mathrm{PM}_{10}$; as well as $1.53 \mathrm{~g} / \mathrm{brick}$ for hydrocarbons. Energy analysis indicate that a significant reduction of $0.9 \mathrm{MJ} / \mathrm{kg}(36 \%)$ in energy use could be achieved by clamp kiln operators, thereby reducing input costs, and significantly reducing atmospheric emissions.
\end{abstract}

Capsule: A model kiln was designed to quantify emission factors, energy metrics and mitigation measures for clamp kiln technology in the clay brick industry

Keywords: emission monitoring; clamp kiln; emission rate; emission factor; model kiln design; clay bricks; energy efficiency for clay bricks; alternative energy for clay bricks

\section{Introduction}

The global brick making industry has been identified as a significant source of air pollution and greenhouse gas emissions in most regions of the world, especially in east, central and south-west Asia; Africa; and Central America (Croitoru and Sarraf, 2012; Ferdausi et al., 2008; Lalchandani, 2012; World Bank, 1998, 1997). Clamp kiln technology, at an industrial scale, is the main technology used for firing bricks in South Africa, and is widely used in various regions of Africa, Asia and Central America. This is due to its relatively simple and affordable technological application during construction, production and post-production phases of brick production i.e. when compared to other brick firing technologies (Ahmad et al., 2011; Akinshipe, 2013; Guttikunda et al., 2013; Maithel et al., 2012; Rajasthan State Pollution Control Board, 2011).

A clamp kiln is basically a temporary structure built with "green bricks"1 to be fired. They (green bricks) are packed in a pyramidshaped formation on top of a foundation layer made of previously fired bricks, which also houses pieces of combustible material (wood, coal, cinder, coke, waste etc.). Few layers of previously fired bricks may be used to enclose the green bricks, in order to reduce heat loss and conserve energy for firing (See Figure A, Supplementary Material). However, clamp kiln technology been globally characterized as a highly polluting and energy inefficient technology; and its utilization, especially at industrial scale, has been discontinued in most developed nations (Akinshipe, 2013; Hashemi and Cruickshank, 2015; Rajasthan State Pollution Control Board, 2012; Raut, 2003). Clamp kiln technology application in South Africa, especially in the industrial or formal brick production sector, has been developed to utilize larger quantity of bricks than elsewhere in Africa, Asia and Central America. These (South African clamp kilns) often utilize several million green bricks, producing an estimated $68-85 \%$ of total clay bricks production in South Africa, amounting to over 4 billion bricks per annum, and accounting for over 12000 skilled and unskilled jobs (CBA, 2015, 2005, 2002).

Pollutants associated with clamp kiln technology include particulate matter $(\mathrm{PM})$, sulphur dioxide $\left(\mathrm{SO}_{2}\right)$, carbon dioxide $\left(\mathrm{CO}_{2}\right)$, nitrogen dioxide $\left(\mathrm{NO}_{2}\right)$, nitrogen oxide (NO), carbon monoxide $(\mathrm{CO})$, metals, tropospheric ozone $\left(\mathrm{O}_{3}\right)$, total organic compounds (TOC) (including ethane, fluorides, methane, volatile organic compounds [VOCs], as well as hazardous air pollutants [HAPs] etc. (Akinshipe, 2013; Assadi et al., 2011; Guttikunda et al., 2013; Hashemi and Cruickshank, 2015; Skinder et al., 2014; USEPA, 1997). These pollutants have been linked to many cases of severe health problems in humans and animals, as well as damage to vegetation, agriculture and land cover (Assadi et al., 2011; Croitoru and Sarraf, 2012; Guttikunda and Khaliquzzaman, 2014; Haack and Khatiwada, 2007; Pariyar et al., 2013; Pokhrel and Lee, 2014).

\footnotetext{
1 "Green Bricks" is a term used to describe bricks that have been processed, dried and ready to be fired.
} 
The challenge associated with emissions from clamp kiln firing include the uncontrollable firing process involved (due to the pseudoenclosed nature of the firing chamber), inadequate abatement technology for mitigating emissions, as well as the localised effect of the emission on the immediate environment as a result of relatively cool emissions i.e. if compared to other industrial processes (Akinshipe, 2013; DEA, 2010; Irm, 2011). In addition, the quantification of emissions from clamp kilns has proven unsuccessful globally, due to inadequate scientific method for estimating pollutant and process metrics from the kiln. These metrics include particulates and gas concentrations, flue gas temperature, flue gas velocity, combustion efficiency, emission rates, emission factors etc. The configuration of a clamp kiln and the mechanism of its firing process make it impracticable to capture and channel flue gases emanating from the kiln, without which measurements cannot be taken. Any attempt to undertake measurements produces severely distorted results due to external environmental and climatic influences such as wind speed, wind direction, rain, humidity and ambient temperature (Cardenas et al., 2009; Darain et al., 2016; Daraina et al., 2013; Irm, 2011; Umlauf et al., 2011).

Furthermore, the contribution of external sources of atmospheric emissions from the brick processing yard and from local and regional land use activities such as agriculture and other industrial processed cannot be adequately quantified and apportioned due to the pseudo-enclosed nature of the clamp kiln firing chamber. Hence, measurement results, as well as dispersion simulations are mostly over estimated, since emissions from external sources cannot be restrained or accounted for (Akinshipe, 2013; Akinshipe and Kornelius, 2017a). As a result of these challenges, previous studies, policies and regulations involving clamp kiln technology have been based on assumptions, estimations as well as inference drawn from similar technologies.

Previous works, such as Akinshipe \& Kornelius (2017a) and Burger \& Breitenbach (2008) investigated the use of atmospheric dispersion simulation and ambient monitoring to attempt simulation and back-calculation of emission rates and emission factors for clamp kilns. The studies utilized passive diffusive samplers to measure ambient $\mathrm{NO}_{\mathrm{x}}, \mathrm{SO}_{2}$ and $\mathrm{PM}_{10}$ concentrations around clamp kiln sites. These studies indicated that reverse dispersion modelling technique and mass balance calculations were in most cases suitable for quantifying $\mathrm{SO}_{2}$ emissions from clamp kilns, but not for $\mathrm{PM}_{10}$ and $\mathrm{NO}_{2}$, since other mobile and stationery sources at clamp kiln and brickmaking facilities release significant quantities of $\mathrm{PM}$ and $\mathrm{NO}_{\mathrm{x}}$ emissions (especially entrained PM from roads and diesel exhaust emission from vehicles and machinery), making allocation of emissions to individual sources difficult for dispersion simulation purposes.

\section{Methodology}

In light of the challenges discussed above, the aim of the study is to design a scientifically acceptable technique for capturing and confining emissions from a simulated clamp kiln in order to comprehensively measure and/or determine emission metrics, parameters and emission factors. In order to achieve this aim, the following objectives were undertaken as scope and approach to the study:

$>$ Design a single source stack configuration for the model kiln that is capable of capturing and channeling flue gases from the kiln through a sampling duct;

$>$ Undertake a series of brick firing and stack monitoring campaigns on the model kiln (at the outlet stack) using varying firing inputs typically used by South African clamp operation;

$>$ Conduct laboratory and computational analysis of input data and measured results in order to generate clamp kiln emission rates, emission factors and other emission metrics;

$>$ Evaluate the energy efficiency of clamp kilns based on analysis of fuel use;

$>$ Compare emissions results from clamp kilns with those from previous literature, as well as results from similar brick firing technologies, in order to evaluate the extent of clamp kiln pollution relative to those firing technologies; and

$>$ Recommend air quality management measures for clamp kilns based on findings of the study.

\subsection{Model Kiln Design}

The model kiln is located in a functional and easily accessible clamp kiln factory. It is built in a secluded location in order to restrict or minimize the influence of external air pollution sources. The model kiln configuration was designed to simulate a transverse slice of a full-scale South African clamp kiln, but with lesser firing capacity of 20000 to 35000 bricks per firing cycle (Figure 1). The design is premised on the notion that the length dimension in a full-scale kiln is much larger than the width; therefore, the lateral gas flow and hence, the energy flow, from the shorter side, will be much lower than the flow from the longer sides. In addition, the base layers of the bricks are packed in a way to allow lateral air flow from the shorter sides of the kiln. Consequently, it is anticipated that, if a transverse slice of the full-scale kiln is isolated by constructing two side walls to provide adequate insulation, conditions similar to those in the full-scale kiln can be replicated in the model kiln (Figure 2). As a result of the simulation, gas flow pattern and energy profile in the model kiln are expected to simulate gas flow pattern and energy profile in the original kiln. Consequently, the rate of combustion, as well as other physical and chemical processes in the model kiln (such as exchange of cold air, release of flue gases, and ignition of the fuel mixed into the bricks etc.), are expected to occur and progress in similar fashion to the original kiln. Thus, the firing process in the model kiln is expected to simulate the firing process in the full-scale clamp kiln. The model kiln is constructed with its semi-enclosed sides to the direction of the prevalent airflow from the north and northwest of the region, in order to allow 
adequate supply of air during brick firing. A green-coloured plastic wire mesh wind shield (shade netting) is installed 5 metres away, to the north and northwest of the model kiln in order to minimize excessive airflow during extreme wind conditions.

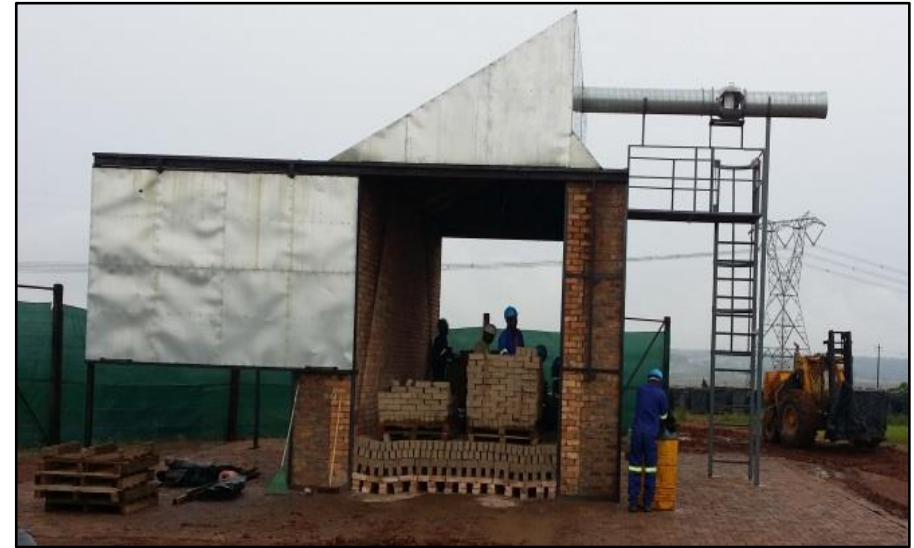

Figure 1: Ongoing model kiln packing process showing horizontal stack, sliding door enclosures, sampling platform and green mesh windshield

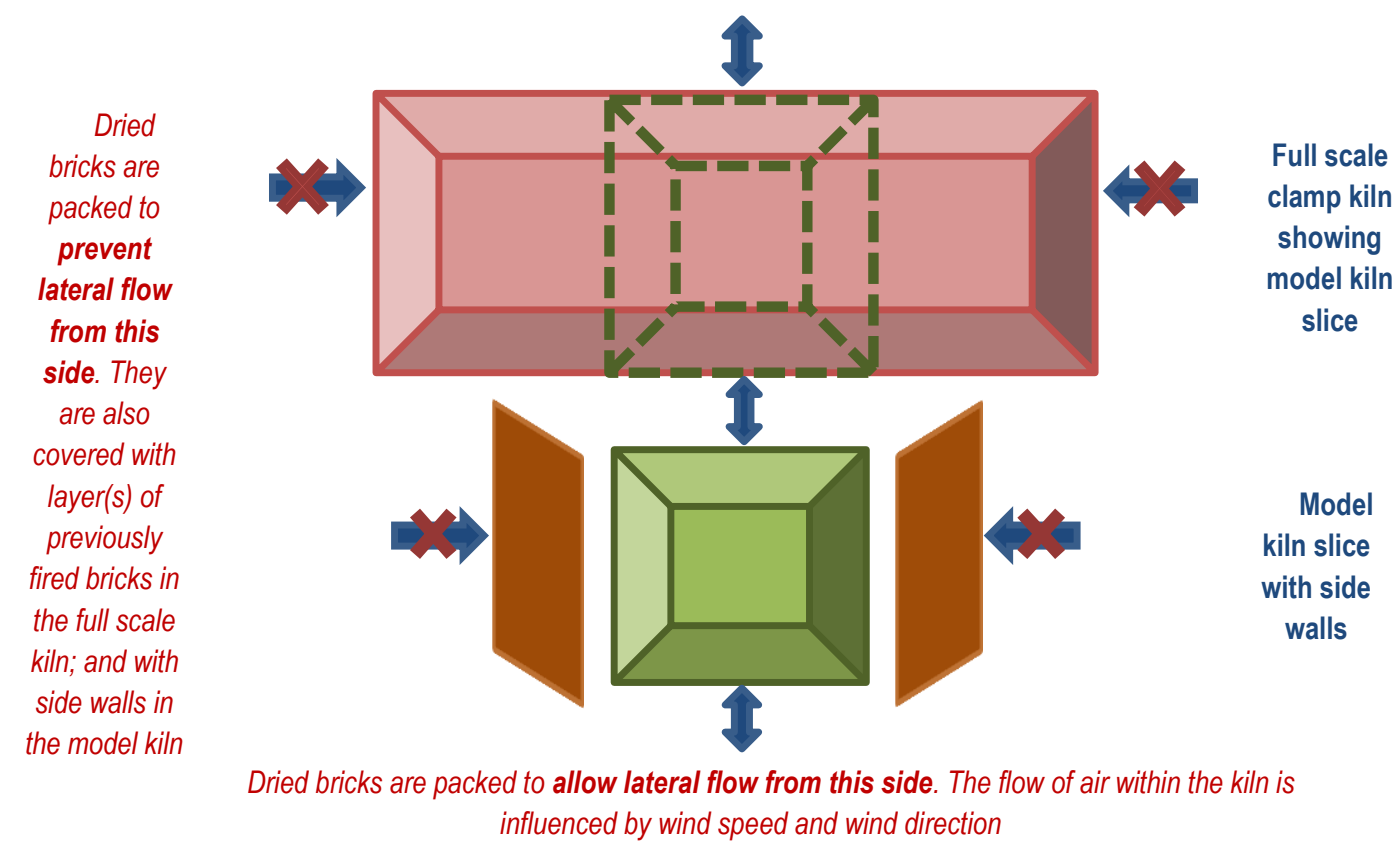

Figure 2: Illustration of air flow in a traditional clamp and the model kiln slice

The top of the kiln is hooded with an insulated galvanised steel cover bearing a horizontal stack outlet, with a cross sectional area of $0.13 \mathrm{~m}^{2}$. A horizontal stack was considered more feasible for the purpose of this study since it minimises the vertical climbing height required for the person taking the measurement to reach the monitoring point and thus contributes to safe operation. The stack is equipped with a "bifurcated case axial" fan which extracts and channels the flue gas through the stack to the monitoring point. The design ensures adequate capture and channelling of the flue gas through the stack, with minimum losses experienced via the semienclosed sides. Galvanized steel sliding side boards are fitted to the open sides of the model kiln wall. These boards are kept opened during packing and unpacking of bricks in the kiln; but are closed for the firing duration and while hourly measurements are taken.

The inlet velocity through the openings (with the "draught" doors closed) is expected to be in the order of $0.5 \mathrm{~m} / \mathrm{s}$, as obtained from the outlet fan curve (Vent-Axia, 2015, 2010). This velocity is less than the normal wind velocities experienced by full-size kilns. The forced draught in the model kiln is therefore not expected to cause a material difference in air supply or flow conditions over the outside wall of the packed kiln when compared to a full-size kiln. Hence, it is not anticipated that there would be significant difference between combustion conditions in the model kiln and a full-scale kiln. Even if differences occur in the flow conditions between the model kiln and the full-size kiln, measurements between the different test firings will be run under comparable conditions. 


\subsection{Stack Monitoring}

A series of thirteen model kiln firing and concurrent stack monitoring campaign was conducted in order to collect emissions data. Measurement and data recording was carried out for the entire duration of each firing campaign; which included hourly measurements for gaseous pollutants ( $\mathrm{CO}, \mathrm{NO}, \mathrm{NO}, \mathrm{NO}_{2}, \mathrm{SO}_{2} \mathrm{PM}, \mathrm{HC}$ and percentage $\mathrm{CO}_{2}$ ) and emission metrics (exit velocity, flowrate, flue gas temperature etc.). For each hourly measurement, readings were taken every second for all the parameters and then averaged over 5- 6 minutes. Thus measurement was considered representative for the entire hour since continuous monitoring was not feasible for the entire hour. Measurements were also taken for the ambient air to allow for possible background input. In measuring gaseous pollutants, the E INSTRUMENTS Model 5500 gas analyzer was utilized. The gas analyzer measures the aforementioned gaseous pollutants by means of electrochemical sensors. It also measures stack gas velocity, volumetric flow rate, excess air and combustion efficiency according to the EPA Method 2 or 2 C (Biarnes et al., 2013; E Instruments, 2008). In addition, PM measurement was undertaken using the Sidepak ${ }^{\text {TM }}$ Personal Aerosol Monitor Model AM510 and the DustTrak ${ }^{\mathrm{TM}}$ DRX Handheld Aerosol Monitor Model 8534.

\subsection{Firing and Energy Variables}

Input and firing conditions, techniques and parameters were varied over each firing and monitoring campaign. These conditions, techniques and parameters are comparable to those obtained at the full scale clamp kiln operation at the factory from where the bricks are sourced. The objective is to simulate the source factory's method of processing, packing and firing, as well as the intrinsic properties of the clay and coal materials from each factory. The variables include the following:

$>$ Source of green bricks - Dried bricks to be fired are obtained from various brick factories across South Africa, with only one brick source utilized per firing campaign;

$>$ Method of bricks processing and packing - The bricks were processed, packed and fired in similar fashion to the technique employed at the source factory;

- Intrinsic properties of green bricks (such as moisture content and clay type) - These varies according to clay source; and

$>$ Sulphur and energy content, and source of fuel used - Clamp kiln energy input parameter varies from one factory to another. The major source of fuel for South African clamp kiln is coal - small nuts coal, carbon fly ash (CFA) and duff coal (CBA, 2005, 2002; Lordan, 2011). Duff coal or CFA are used as "body fuel" (that is, are mixed into the clay during processing), while the small nuts or peas serve as the "external fuel" in the bottom ignition layer of the kiln (scintle).

Packing of bricks into the kiln was done manually by six to ten men (for each batch of firing), with the aid of equipment such as forklifts and front-end loaders. Start-up of the firing process was done for most batches with the use of a 'fire-box', which is basically a stack of bricks housing sufficient amount of coal to start the firing process. Batch 3 and batch 12 operator utilized diesel (20 litres) and natural gas respectively, to start-up their firing process.

\section{Results and Discussions}

The following sections provide results of thirteen measurement campaigns conducted. Batch 1 results are not included due to a complete shutdown of the exercise few hours after start-up. Correlation analysis of data was performed using the GNU PSPP TM version 0.9 and Minitab ${ }^{\mathrm{TM}} 18.1$ software at $95 \%$ confidence interval. Concentration/time plots for all emission metrics are shown in Supplementary materials.

\subsection{Brick Appearance and Emission Metrics}

Physical observations recorded for batch 2 to batch 13 indicates that the bricks were, in most cases, adequately fired in the model kiln. Physical examination of fired bricks (with respect to softness/hardness, strength, sound and core colour) from the model kiln showed similarities with bricks fired in conventional clamp kilns. Laboratory evaluation of fired bricks (in terms of compressive strength and water absorption test) indicated that the bricks fired in the model kiln achieved compressive strength and water absorption test values that are well within typical industry ranges, as well as compliant with industry requirement and masonry brick dimensions. Approximately $70-90 \%$ of the total brick fired in the model kiln across batch 2 to batch 13 were considered adequately fired.

Flue-gas exit temperature profile for batch 2 to batch 13 is shown in Figure B, Supplementary Material. The various profiles show similar temperature trends, with batch 2 and batch 12 exhibiting extreme values. Temperatures generally initiate at ambient levels; gradually rising to a peak during the second and third quarter of the firing period; and dropping to ambient levels again towards the end of the cycle. The temperature/time plot shows a negatively skewed polynomial regression curve (leaning towards the end of the firing cycle). A slight rise and fall in temperature levels, following a diurnal and nocturnal temperature rise and dip is also observed. A highest temperature of $409^{\circ} \mathrm{C}$ was recorded during batch 2 firing.

The velocity profile does not exhibit any consistent trend over the firing cycle. Levels (ranging from about $3 \mathrm{~m} / \mathrm{s}$ to $20 \mathrm{~m} / \mathrm{s}$ ) rose and fell over the firing period for all batches. The velocity/time plot shows asymmetrical polynomial regression curves with little or no consistency throughout the firing duration. This suggests that flue gas velocity at the stack is controlled by the extraction fan and environmental factors such as winds, rather than by convective processes inside the kiln. A velocity variability plot is shown in Figure $B$ in Supplementary Material, indicating a steep variability between the lower and upper quartile range, and a median of $10 \mathrm{~m} / \mathrm{s}$. At 
high wind speeds, visible smoke can be seen coming out from under the semi-enclosed air inlet at the opposing side to the wind direction.

\subsection{Emission Concentration and Emission Factors}

Hourly emission concentrations and process metrics were recorded for each batch over the entire firing cycle (8 to 14 days). Calculated emissions concentrations $\left(\mathrm{mg} / \mathrm{m}^{3}\right)$ from measured data and process metrics are included in Table A and Table B in Supplementary material. Calculated emissions concentrations standardized to normal conditions are presented in Table 1, while histogram of $\mathrm{CO}, \mathrm{NO}_{x} / \mathrm{NO}$ and $\mathrm{SO}_{2}$ emissions concentrations and flue gas temperature are presented in Figure 3 (for batch 3 ). Complete histograms and concentration/time plots for all pollutants and across all batches are presented in Supplementary Material, while emission variability plot for all batches is shown in Figure 4.

Measured CO concentration shows similar trends across various batches, with concentration initiating at low levels; gradually rising and reaching peak concentrations within 30 to 100 hours (i.e. first and second quarter of firing duration), and gradually falling again to low levels towards the end of the firing cycle. In most cases, the concentrations show a positively skewed histogram (leaning towards lower emissions), typical of kiln combustion process which gradually ignites fuel and carbonaceous compounds in the bricks; and burning out over time. Since physical examination (by touch) of the external fuel in the 'scintle' layer of the kiln indicated that this burns off within one to two days of firing, implying that a large proportion of $\mathrm{CO}$ emissions during peak periods are from combustion of the external fuel in the 'scintle' layer. This suggests incomplete combustion and inefficient use of fuel for firing. Batch 3 displays the best indication of consistent emissions over the firing period (since shorter bars and a centred median in the variability plot is an indication of lower variability and consistent emissions). Batch 2, batch 11 and batch 12 show extreme levels of data variability, which suggest that these batches were inefficiently or unevenly combusted as a result of unevenly mixed fuel or inhomogeneous clay in raw bricks.

Measured $\mathrm{NO}_{2}$ emission was not detected throughout the entire firing duration. This is attributed to the high temperature occurring within the kiln, since it has been established that NO is preferentially formed from combustion of fossil fuels at high temperatures. In a typical combustion chamber, thermodynamic equilibrium is formed between nitrogen, oxygen, $\mathrm{NO}$ and $\mathrm{NO}_{2}$ at temperatures in the combustion ranges. Hence, the higher the temperature, the more the equilibrium shifts to the production of $\mathrm{NO}$ rather than $\mathrm{NO}_{2}$ (Bartok and Sarofim, 1991; Heywood, 1988; USEPA, 1999).

During Batches 3, 5, 8 and 11 firing cycle, measured NO concentration shows slight trends across batches, with concentration initiating at low levels, with a gradual rise in levels during the first and second quarter of the firing cycle; and reaching peak concentrations within $80-120$ hours (i.e. second and third quarter of firing), and gradually falling again to low levels towards the end of the firing cycle. Batches 2, 4, 6, 9, 10 and 12 do not show any regularity across the firing duration. The measured NO concentrations for these batches do not exhibit any consistent trends; with concentrations initiating at mid-levels, rising and falling over the firing period. The initial mid-level concentrations observed during these batches may be attributed to combustion of the external fuel in the 'scintle' layer. A sudden and irregular spike in concentration level was also observed during Batch 2 firing. The cause of this could not be determined. In most cases, the concentrations show a positively skewed histogram (leaning towards lower emissions), typical of kiln combustion process which gradually ignites fuel in the bricks; and burning out over time. Batch 3 and batch 8 displayed the best indication of consistent and steadier emissions over the firing period; while batches 2, 6 and 12 show high levels of data variability, which suggest that these batches were inefficiently fired due to unevenly mixed fuel or inhomogeneous clay in raw bricks.

Measured $\mathrm{PM}_{10}$ concentration does not exhibit any consistent trend, with concentration initiating at mid to high levels, rising and falling over the firing period. In most cases, the concentrations show a positively skewed histogram (leaning towards lower emissions), typical of kiln combustion process which gradually ignites fuel and release particulates as combustion proceeds; and burns out over time. $\mathrm{PM}_{10}$ adjustment measurement adjustment is described in Figure $\mathrm{C}$, Supplementary Material; while the factor

Measured $\mathrm{SO}_{2}$ concentration shows similar trends across batches, with concentration initiating at low levels; gradually rising and reaching peak concentrations within $80-120$ hours (i.e. second and third quarter of firing duration), and gradually falling again to low levels towards the end of the firing cycle. In most cases, the concentrations show a positively skewed histogram (leaning towards lower emissions), also typical of kiln combustion process which gradually ignites fuel and sulfur compounds in the bricks; and burning out over time. Occasional spikes in $\mathrm{SO}_{2}$ levels are observed at the start of the firing cycle, which is an indication of the release of sulfur from combustion of the fire-box and the external fuel in the 'scintle' layer. Thereafter, consistent zero emission is recorded for a period lasting $3-6$ days across different batches, and then a sudden and consistent spike in levels is recorded, peaking within $1-2$ days and dipping again to ambient levels towards the end of the firing cycle. The sudden $\mathrm{spike}$ in $\mathrm{SO}_{2}$ levels is most likely due to the oxidation of the pyrite component $\left(\mathrm{FeS}_{2}\right)$ in the clay material, oxidation of the sulfur component of the internal fuel (coal that is mixed with the clay material during brick processing) and the dissociation of $\mathrm{CaSO}_{4}$ in an oxidizing environment within the clay material to release $\mathrm{SO}_{2}$ (Akinshipe and Kornelius, 2016, 2015; Brosnan and Sanders, 2005; Brownell, 1960, 1949; Gredmaier et al., 2011; Grim and Johns, 1951; Klepetsanis et al., 1999). SO 2 emission variability plot indicates positively skewed $\mathrm{SO}_{2}$ emissions (leaning towards lower $\mathrm{SO}_{2}$ concentrations). Batch 8 displays the best indication of consistent emissions over the firing period. Batches 2, 10 and 12 show extreme levels of data variability, which suggest that these batches were inefficiently fired. 
Calculated percentage $\mathrm{CO}_{2}$ results exhibit little consistency across the firing cycle; with levels generally maintained between 0 and 8 $\%$ over the firing period. The highest average $\mathrm{CO}_{2}$ percentages are recorded during batches $2,6,10$ and 12 , while mean percentage $\mathrm{CO}_{2}$ across all batches is $0.48 \%$.

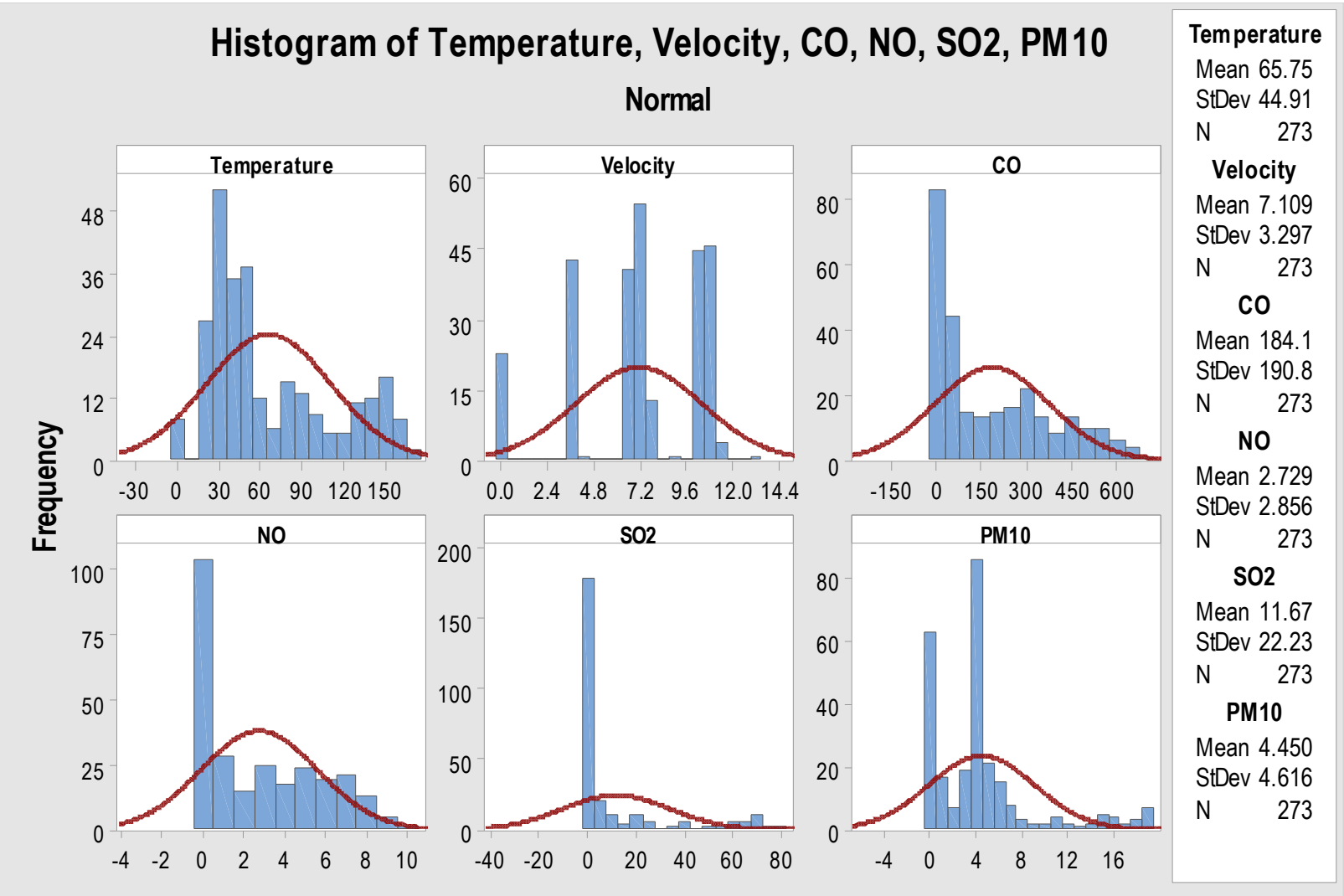

Figure 3: Histogram of $\mathrm{CO}, \mathrm{NO}_{x} / \mathrm{NO}, \mathrm{SO}_{2}$ and $\mathrm{CO}_{2}$ emissions concentrations and flue gas temperature and Velocity (batch 3 used for illustration)
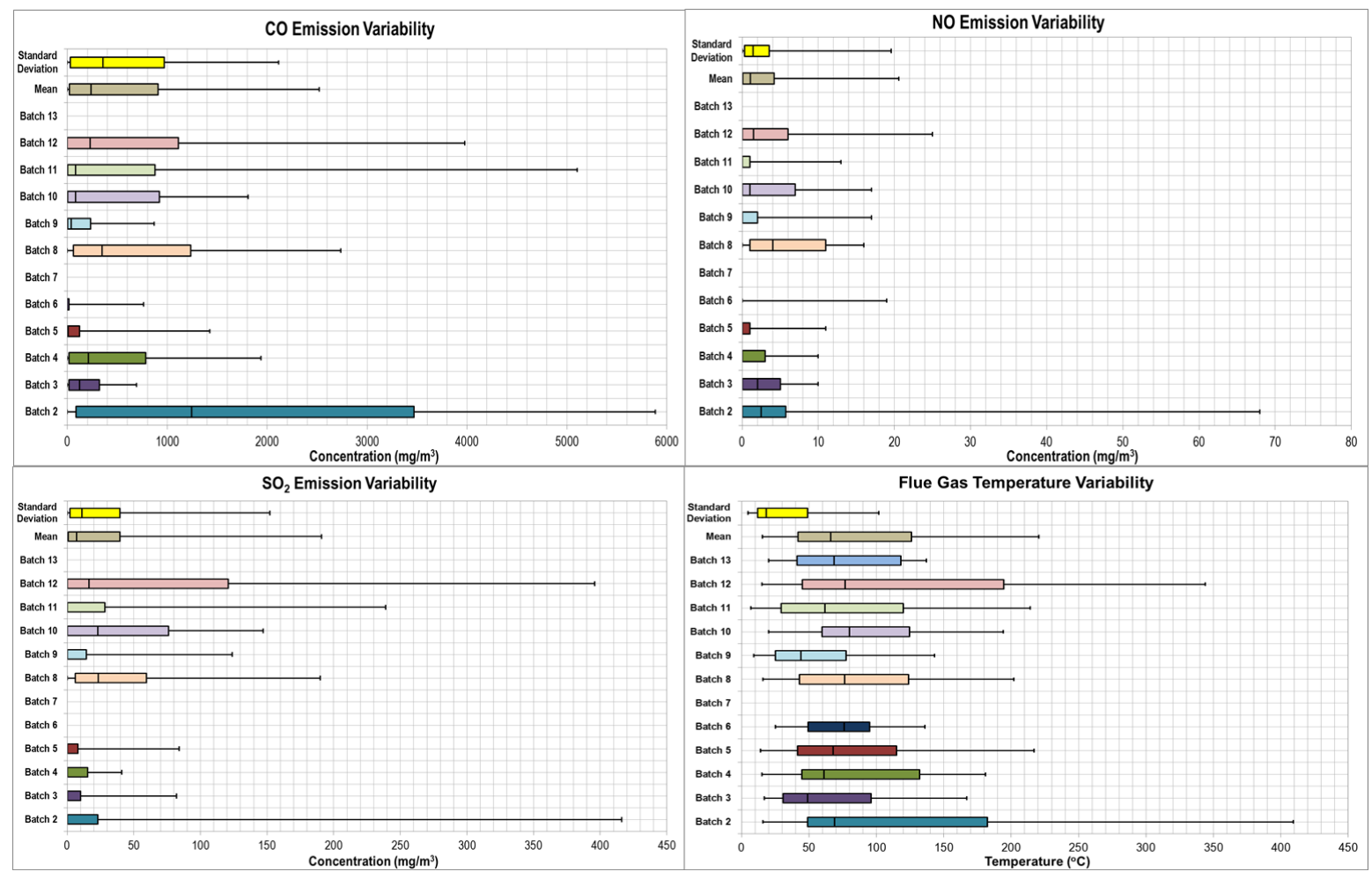

Figure 4: $\mathrm{CO}, \mathrm{NO}, \mathrm{SO}_{2}$ emissions and flue gas temperature variability plot 
Table 1: Measured average concentration over the firing period

\begin{tabular}{|c|c|c|c|c|c|c|c|}
\hline \multicolumn{8}{|c|}{ Concentration in $\mathrm{mg} / \mathrm{m}^{3}$ (mean $\pm \mathrm{SD}$ ) } \\
\hline Batch & $\mathrm{CO}$ & $\mathrm{NO}_{\mathrm{x}}$ & NO & $\mathrm{NO}_{2}$ & $\mathrm{SO}_{2}$ & $\mathrm{CO}_{2}$ & $\mathrm{HC}$ \\
\hline 2 & $1810 \pm 1730$ & $6.00 \pm 11.5$ & $6.00 \pm 11.5$ & 0.00 & $34.5 \pm 72.3$ & $21100 \pm 21300$ & ND \\
\hline 3 & $190 \pm 191$ & $2.80 \pm 2.90$ & $2.80 \pm 2.90$ & 0.00 & $12.0 \pm 22.4$ & $970 \pm 3880$ & ND \\
\hline 4 & $458 \pm 540$ & $1.50 \pm 2.10$ & $1.50 \pm 2.10$ & 0.00 & $7.80 \pm 12.0$ & $7760 \pm 7760$ & ND \\
\hline 5 & $113 \pm 214$ & $1.20 \pm 2.10$ & $1.20 \pm 2.10$ & 0.00 & $10.1 \pm 18.3$ & $4460 \pm 7760$ & ND \\
\hline 6 & $196 \pm 161$ & $3.80 \pm 1.20$ & $3.80 \pm 1.20$ & 0.00 & ND & $1160 \pm 15500$ & ND \\
\hline 7 & ND & ND & ND & 0.00 & ND & ND & $48.6 \pm 58.3$ \\
\hline 8 & $685 \pm 767$ & $5.60 \pm 5.00$ & $5.60 \pm 5.00$ & 0.00 & $45.1 \pm 50.9$ & $15100 \pm 13600$ & ND \\
\hline 9 & $157 \pm 210$ & $1.20 \pm 2.40$ & $1.20 \pm 2.40$ & 0.00 & $16.8 \pm 30.9$ & $7760 \pm 9700$ & ND \\
\hline 10 & $414 \pm 554$ & $3.80 \pm 4.40$ & $3.80 \pm 4.40$ & 0.00 & $43.2 \pm 47.1$ & $12400 \pm 17500$ & ND \\
\hline 11 & $558 \pm 909$ & $1.10 \pm 2.10$ & $1.10 \pm 2.10$ & 0.00 & $24.3 \pm 45.3$ & $7370 \pm 9700$ & ND \\
\hline 12 & $786 \pm 1070$ & $3.50 \pm 4.60$ & $3.50 \pm 4.60$ & 0.00 & $75.6 \pm 108$ & $13900 \pm 17500$ & ND \\
\hline 13 & ND & ND & ND & 0.00 & ND & ND & ND \\
\hline Mean \pm SD & $395 \pm 513$ & $2.70 \pm 3.00$ & $2.70 \pm 3.01$ & 0.00 & $29.4 \pm 41.9$ & $9220 \pm 12500$ & $48.6 \pm 58.3$ \\
\hline
\end{tabular}

NOTE: a "ND" means "no data"; "SD" means "standard deviation" b All NO $\mathrm{N}_{2}$ measurements recorded zero values

\subsection{Emission rates and emission factors}

Emission rates and emission factors are calculated from hourly emission concentrations. Emission rates are given in gram per second ( $\mathrm{g} / \mathrm{s}$ ) and gram per second per brick fired ( $\mathrm{g} / \mathrm{s}$ brick); while emission factors are given as gram of pollutant released per brick fired ( $\mathrm{g} / \mathrm{brick}$ ) and gram of pollutant released per kilogram of brick fired $(\mathrm{g} / \mathrm{kg}$ ). For each of the variables, the mean of the distribution was taken as the most appropriate measure of central tendency, since various emission releasing reactions and processes occur in the kiln at different period during the firing cycle. These reactions and processes include the following:

$>$ release of 'mechanical water' and 'combined water';

$>$ combustion of external fuel in the base layer and the internal fuel mixed into the bricks;

$>$ dissociation of carbonates in the clay material;

$>$ oxidation conditions leading to dissociation of $\mathrm{CaSO}_{4}$ and release of $\mathrm{CO}_{2}$ (and eventually $\mathrm{SO}_{2}$ ); or retention of $\mathrm{CaSO}_{4}$ and $\mathrm{FeS}_{2}$ in a reducing environment to give off $\mathrm{CO}$ and $\mathrm{H}_{2}$; and

$>$ Destruction or development of lattice structure and change in crystal phase of the clay material.

Emission concentration and emission factor exhibit little or no similarity across firing campaigns; which may be attributed to the significantly varying input and firing conditions applied to individual batches. High standard deviations, as well as high range of data spread indicate that emissions and process metrics from clamp kilns are sensitive to these input variables. Measured results also indicate that the external fuel in the base layer of the kiln is the major source of atmospheric emissions, since the coal mixed into the clay during processing only starts to react with the clay components at high temperature range of $350-950{ }^{\circ} \mathrm{C}$ to form volatile hydrocarbons and carbonaceous residues (Akinshipe and Kornelius, 2017b; Cultronea et al., 2003; Gredmaier et al., 2011; Rowden, 1964). The carbonaceous residue will only be further combusted to emit $\mathrm{CO}$ or $\mathrm{CO}_{2}$ if the following favourable conditions in the kiln occur: availability of excess air in the combustion chamber to maintain an oxidising environment; a high cross sectional area of clay material being exposed to combustion, as well as adequate spacing; and uniformity in the rate of combustion, so as to ensure adequate penetration of the clay brick and ignition of the carbon in the core of the bricks (Akinshipe and Kornelius, 2017b; Grim and Johns, 1951; Rowden, 1964).

\subsection{Sulfur Mass Balance and Energy Efficiency Analysis}

Sulfur mass balance analysis was conducted by accounting for the quantity of sulfur entering (sulfur input) and exiting (sulfur output) the firing system, thereby providing a reference technique for assessing the model kiln's efficiency in capturing the sulfur emitted to the atmosphere (these comprise of the emissions captured into the stack monitoring duct and emissions that escape from underneath the semi-enclosed sliding doors). Sulfur balance method was used instead of carbon balance method; since carbon balance utilizes organic carbon measurements that are sensitive to temperature and dilution levels and are measured at conditions that mimic conditions in the atmosphere after emission. The gas analyser that was available for measurement in this study does not allow for dilution levels and provides estimated $\mathrm{CO}_{2}$ percentages. Calculating carbon balance using this method will result in higher levels of uncertainties than sulfur balance calculations.

In an ideal system, the percentage of output sulfur to input sulfur in the firing system will approach $100 \%$, with the unaccounted percentage equivalent to the emissions that escapes underneath the semi-enclosed sliding doors. In reality, sulfur mass balance result shows varying percentages across various batches. Batch 2 and batch 9 mass balance results are close to the ideal condition 
(100\%); while batches 3, 4, 8 and 11 mass balance results deviate rather significantly. Also, batches 5, 10 and 12 results exhibit extreme divergence (non-conforming batches), while batches 6, 7 and 13 results could not be calculated due to characteristic errors. In addition, laboratory results for non-conforming batches indicate an increase in the quantity of sulfur retained in fired bricks, when compared to the green bricks; implying retention of sulfur in the fired brick rather than anticipated release of emissions. Likely factors influencing the non-conformity of these batches' analysis to the ideal system include:

- The complexity regarding oxidation and/or reduction reaction in the firing chamber. Generally, dominant oxidation conditions favour the release of sulfur as $\mathrm{SO}_{2}$ emissions, while reduction conditions favour sulfur retention in brick as $\mathrm{CaSO}_{4}$ and $\mathrm{CaS}$.

- In order for mass balance analysis to be accurate, homogeneity during processing and mixing of clay bricks is required so as to ensure that the constituents of the clay and fuel material (including sulfur compounds) are evenly distributed across the whole batch. However, homogeneity may not be achieved since only two brick samples in over 20000 bricks were analysed per batch.

Consequently, in order to calculate a useable average mass balance percentage, statistical analysis was performed to determine the batches whose mass balance result lie within $95 \%$ confidence interval of the assumed true mean i.e. $100 \%$. Assuming that batch 2 to batch 13 mass balance percentages represent samples of a population having a true mean of $100 \%$ (the ideal mass balance percentage), a 95 percent confidence interval estimate of true mean is given by Ross (2014) as follows:

$$
P\left\{\bar{X}-1.96 \frac{\sigma}{\sqrt{n}}<\mu<\bar{X}+1.96 \frac{\sigma}{\sqrt{n}}\right\}=.95
$$

Where: $\mathrm{P}=$ probability; $\bar{X}=$ sample mean; $\mu=$ true mean; $\sigma=$ standard deviation and $\mathrm{n}=$ number of samples.

The mean of the batches that are within the $95 \%$ confidence interval range of the assumed true mean (100\%) yields $84.2 \%$, which may be considered the statistical mean efficiency of capturing and channelling flue gas to the measuring point by the model kiln. Consequently, the statistical mean percentage of the emissions escaping underneath the semi-enclosed sliding doors will be equivalent to $15.8 \%$. This average was taken as the overall indicator of the proportion of flue gas that escapes from underneath the semi-enclosed side boards, and was utilized in correcting for final emission metrics.

A calibration factor of 0.61 was obtained from literature to correct PM concentration obtained from the DustTrak and SidePak monitors to gravimetric concentrations. This calibration factor was obtained by McNamara et al (2011) from controlled laboratory wood stove emissions and is considered the most similar aerosol found in literature to the model kiln emissions (refer to Supplementary material). Final corrected emission factors (mean \pm standard deviation) were quantified as $22.5 \pm 18.8 \mathrm{~g} / \mathrm{brick}$ for $\mathrm{CO}, 0.14 \pm 0.1 \mathrm{~g} / \mathrm{brick}$ for $\mathrm{NO}, 0.0 \mathrm{~g} / \mathrm{brick}$ for $\mathrm{NO}_{2}, 0.14 \pm 0.1 \mathrm{~g} / \mathrm{brick}$ for $\mathrm{NO}_{\mathrm{x}}, 1.07 \pm 0.7 \mathrm{~g} / \mathrm{brick}$ for $\mathrm{SO}_{2}, 378 \pm 223 \mathrm{~g} / \mathrm{brick}$ for $\mathrm{CO}_{2}$, $0.96 \pm 0.5 \mathrm{~g} / \mathrm{brick}$ for $\mathrm{PM}_{10}$; as well as $1.53 \mathrm{~g} / \mathrm{brick}$ for hydrocarbons (calibrated to propane emissions) and $0.96 \mathrm{~g} / \mathrm{brick}$ for $\mathrm{PM}_{15}$, $\mathrm{PM}_{4}, \mathrm{PM}_{2.5}$ and $\mathrm{PM}_{1}$ (Table 2). The similarity in $\mathrm{PM}_{1}, \mathrm{PM}_{2.5}, \mathrm{PM}_{4}, \mathrm{PM}_{10}$ and $\mathrm{PM}_{15}$ emission factors indicate that the combustion $\mathrm{PM}$ is composed of extremely fine PM - since it is made up of nucleotides and particles that are yet to coagulate in the atmosphere (refer to Figure $D$ and Literature A, Supplementary Material).

A dendrogram of cluster analysis for pollutants emission factors is presented in Figure 6 , showing associations among various pollutants across batch 2 to batch 13. The relationship or association among the pollutants can be linked to the processes and mechanisms of the pollutant generation (in this case, mainly combustion conditions and/or properties of fuel and clay material used). A strong association is observed between high-temperature releasing pollutants such as $\mathrm{SO}_{2}$ and $\mathrm{NO}_{\mathrm{x}} / \mathrm{NO}_{2}$, while a weak association is observed between $\mathrm{CO}$ and $\mathrm{CO}_{2}$ emissions, since $\mathrm{CO}$ is released by incomplete combustion, while $\mathrm{CO}_{2}$ release is mostly fuel (carbon) dependent under complete combustion conditions. For PM emission, the weak association relative to other pollutants suggests that its release is not directly linked to the mechanisms associated with other pollutants (incomplete combustion, high temperature or fuel content).

Furthermore, correlation analysis was conducted using both Pearson and Spearman rank correlation to evaluate the strength of the sensitivity of flue gas emission concentration and process metrics to energy inputs across batch 2 to batch 13. The outcome of the correlation analysis indicate that flue gas output metrics, including temperature, oxygen reference, percentage $\mathrm{CO}_{2}$, as well as $\mathrm{CO}$, $\mathrm{NO}_{x}$ and $\mathrm{SO}_{2}$ concentrations are sensitive (moderate to strong correlation) to the external energy input (Figure 5). Output metrics are only slightly sensitive to internal and total energy. Consequently, efforts to evaluate the correlation between energy input and output metrics were focused on the external energy. Batch 3 energy analysis produced the best performance in terms of external energy to output metrics sensitivity, while batch 2 performed the poorest.

Comparing the current South African industry SEC - 3.4 MJ/kg (Akinshipe and Kornelius, 2017b) to batch 3 SEC - $2.5 \mathrm{MJ} / \mathrm{kg}$ (since batch 3 produced the best energy performance) and to the average SEC from this study $-2.6 \mathrm{MJ} / \mathrm{kg}$; the significant reduction of 0.8 $-0.9 \mathrm{MJ} / \mathrm{kg}(32 \%-36 \%)$ indicates that the industry could achieve significant reduction in energy use, thereby potentially reducing cost of energy input, and also, significantly reducing the quantity of atmospheric emissions. Based on this potential reduction in energy use, 27528 tons of $\mathrm{CO}$ emission, 171 tons of $\mathrm{NO}$ emission, 0 ton of $\mathrm{NO}_{2}$ emission, 1310 tons of $\mathrm{SO}_{2}$ emission, 463174 tons of $\mathrm{CO}_{2}$ emission and 1873 tons of hydrocarbons emission were quantified as potential annual reduction in South African clamp kilns. 


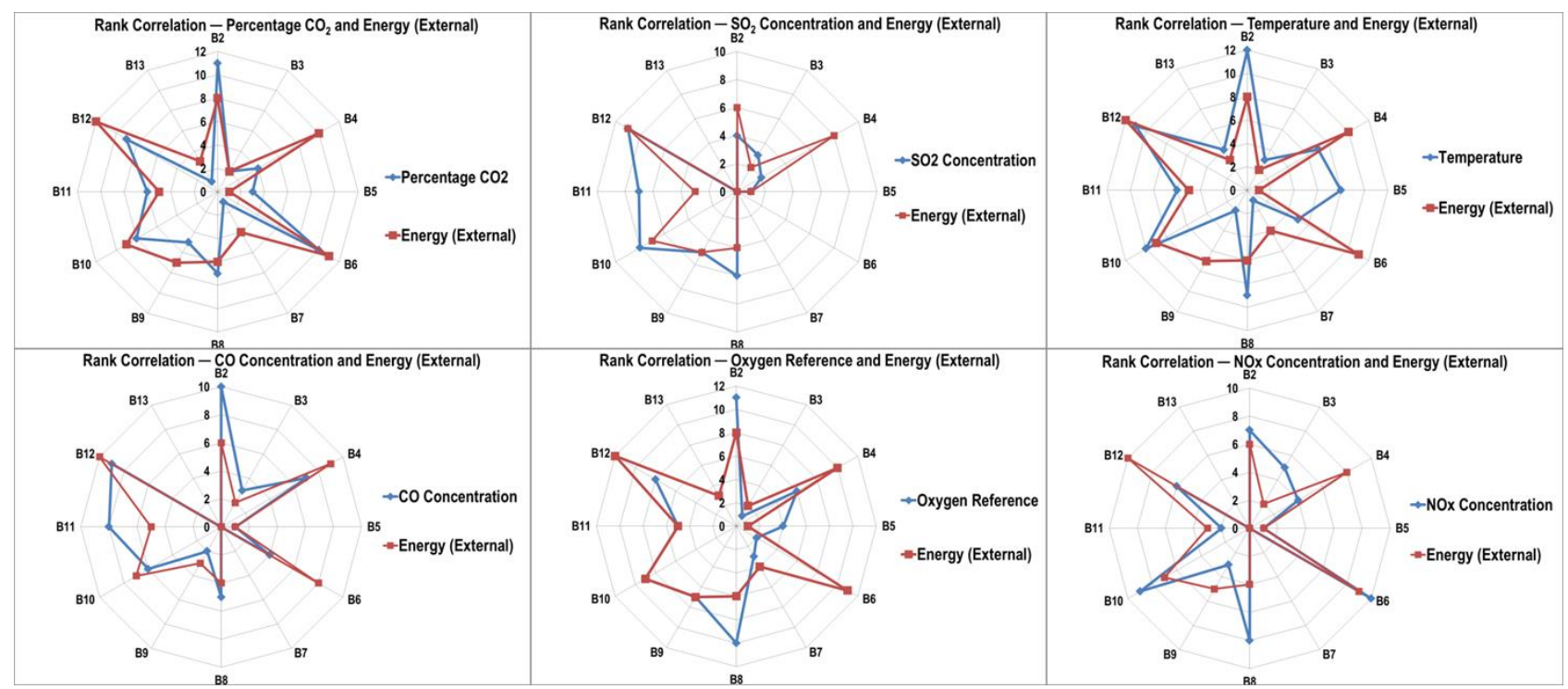

Figure 5: Rank correlation - External energy against output metrics (all batches show moderate to strong correlation, while batches 6, 7 and 13 exhibit poor correlations)

Table 2: Final emission rates and emission factors corrected for occasional losses from underneath the sideboards

\begin{tabular}{|c|c|c|c|c|c|c|c|c|}
\hline \multirow{2}{*}{$\begin{array}{c}15.8 \% \\
\text { correction }\end{array}$} & \multicolumn{2}{|c|}{$g / s$} & \multicolumn{2}{|c|}{ g/s brick } & \multicolumn{2}{|c|}{ g/brick } & \multicolumn{2}{|c|}{$\mathrm{g} / \mathrm{kg}$ of fired bricks } \\
\hline & Mean & SD & Mean & SD & Mean & SD & Mean & SD \\
\hline $\mathrm{CO}$ & $7.99 \times 10^{-1}$ & $6.60 \times 10^{-1}$ & $2.78 \times 10^{-5}$ & $2.08 \times 10^{-5}$ & 22.5 & 18.8 & 7.83 & 6.65 \\
\hline $\mathrm{NO}_{\mathrm{x}}$ & $4.52 \times 10^{-3}$ & $2.43 \times 10^{-3}$ & $1.62 \times 10^{-7}$ & $1.10 \times 10^{-7}$ & 0.14 & 0.10 & 0.05 & 0.03 \\
\hline NO & $4.52 \times 10^{-3}$ & $2.43 \times 10^{-3}$ & $1.62 \times 10^{-7}$ & $1.10 \times 10^{-7}$ & 0.14 & 0.10 & 0.05 & 0.03 \\
\hline $\mathrm{NO}_{2}$ & 0.00 & 0.00 & 0.00 & 0.00 & 0.00 & 0.00 & 0.00 & 0.00 \\
\hline $\mathrm{SO}_{2}$ & $4.17 \times 10^{-2}$ & $3.13 \times 10^{-2}$ & $1.51 \times 10^{-6}$ & $1.16 \times 10^{-6}$ & 1.07 & 0.66 & 0.38 & 0.25 \\
\hline $\mathrm{CO}_{2}$ & $1.50 \times 10^{1}$ & $7.64 \times 10^{0}$ & $5.02 \times 10^{-4}$ & $3.12 \times 10^{-4}$ & 378 & 223 & 132 & 79.7 \\
\hline $\mathrm{HC}$ & $5.10 \times 10^{-2}$ & ND & $1.74 \times 10^{-6}$ & ND & 1.53 & ND & 0.45 & ND \\
\hline $\mathrm{PM}_{10}$ & $3.24 \times 10^{-2}$ & $1.51 \times 10^{-2}$ & $1.27 \times 10^{-6}$ & $6.48 \times 10^{-7}$ & 0.96 & 0.47 & 0.34 & 0.17 \\
\hline $\mathrm{PM}_{15}$ & $3.24 \times 10^{-2}$ & ND & $1.27 \times 10^{-6}$ & ND & 0.96 & ND & 0.34 & ND \\
\hline $\mathrm{PM}_{4}$ & $3.24 \times 10^{-2}$ & ND & $1.27 \times 10^{-6}$ & ND & 0.96 & $\mathrm{ND}$ & 0.34 & ND \\
\hline $\mathrm{PM}_{2.5}$ & $3.24 \times 10^{-2}$ & ND & $1.27 \times 10^{-6}$ & ND & 0.96 & ND & 0.34 & ND \\
\hline $\mathrm{PM}_{1}$ & $3.23 \times 10^{-2}$ & ND & $1.27 \times 10^{-6}$ & ND & 0.96 & ND & 0.33 & ND \\
\hline
\end{tabular}

NOTE: 'ND' means "no data". 'SD' means standard deviation. HC emission is calculated from one batch of firing and calibrated to propane emissions (batch 7)

Final emission factors from this study were compared with applicable and available emission factors obtained from literature - refer to Table D and Table E, Supplementary Material - for different clay brick firing technologies, including down draught kiln (Asia), Bull's trench kiln (Asia), vertical shaft brick kiln (Asia), tunnel kiln (Asia), fixed chimney Bull's trench kiln (Asia), zig-zag kiln (Asia), clamp kilns (Asia) and coal-fired kiln (US). CO emission factor for clamp kiln from the current study, although comparable to the $\mathrm{DDK}$, is higher than emission factors obtained from literature for various firing technologies. With respect to $\mathrm{SO}_{2}$ emissions, kiln technologies are ranked from lowest to highest in terms of potential for atmospheric pollution as follows: Zig-zag < SA clamps < Vertical shaft < US coal-fired < Fixed chimney Bull's trench < Tunnel $\left(\mathrm{SO}_{2}\right.$ analysis should be taken with caution since $\mathrm{SO}_{2}$ emission is directly dependent on sulfur content of fuel and clay material). $\mathrm{NO}_{\mathrm{x}}$ emission factor is lower than the USEPA coal fired kiln by a factor of six. It can be inferred from this analysis that South African clamp kiln emissions are extremely high with respect to CO emissions (higher than all technology available for comparison); and moderate in terms of $\mathrm{SO}_{2}, \mathrm{CO}_{2}$ and $\mathrm{PM} / \mathrm{PM}_{10}$ emissions. $\mathrm{NO}$ x emissions are considered to be extremely low when compared to US coal fired kilns. Based on available emission metrics, the various kiln technologies were ranked from lowest to highest in terms of potential for atmospheric pollution as follows: Zig-zag < Vertical shaft < South African Clamp < US coal-fired < Fixed chimney Bull's trench < Tunnel < Asian Clamps < Down draft < Bull's trench. 


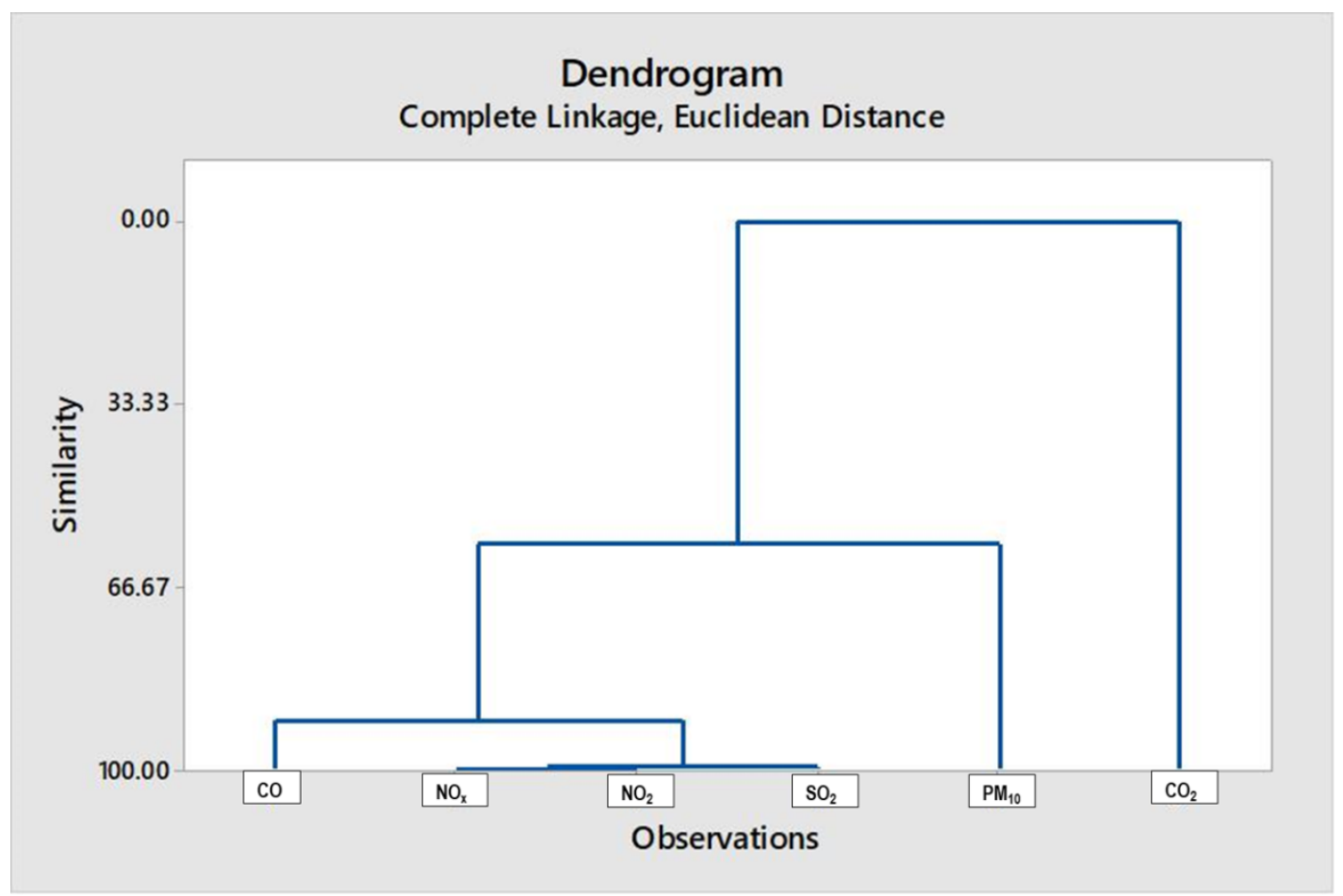

Figure 6: Dendrogram of cluster analysis for pollutant emission factors showing associations among various pollutants across Batch 2 to Batch 13

\subsection{Relationship between Emissions Metrics}

Several flue gas emission metrics were analysed in order to determine their relationships and relate it to chemical and thermodynamic processes occurring within the firing chamber of the model kiln. Correlation analysis (Table 3) was conducted using both Pearson and Spearman rank correlation to evaluate the relationships between the following emission metrics:

- Flue gas temperature and CO emissions: Pearson and Spearman rank correlation indicate weak and very weak negative correlation between flue gas temperature and $\mathrm{CO}$ emissions across various batches (excluding batch 12 that shows a very poor positive correlation). The weak negative correlation corroborates literature claims that carbonaceous compounds are burnt off at the early stages of firing before optimum temperature is reached (i.e. before $300{ }^{\circ} \mathrm{C}$ ).

- Flue gas temperature and $\mathrm{SO}_{2}$ emissions: Pearson and Spearman rank correlation indicate medium to very strong positive correlation between flue gas temperature and $\mathrm{SO}_{2}$ emissions across batches (excluding batch 5 that shows a poor positive correlation). Strong positive correlation corroborates literature claims that $\mathrm{SO}_{2}$ is retained in the brick at lower firing temperatures. Hence, higher temperatures will result in release of higher quantity of $\mathrm{SO}_{2}$ emissions.

- Flue gas temperature and $\mathrm{NO}_{\mathrm{x}}$ emissions: Pearson and Spearman rank correlation indicate very poor to strong positive correlation between flue gas temperature and $\mathrm{NO}_{\mathrm{x}}$ emissions across batches 2 to 13 (excluding batch 8 that shows a poor negative correlation). Though the correlation results suggests a slight linear relationship between flue gas temperature and $\mathrm{NO}_{\mathrm{x}}$ emissions, a distinct relationship has not been established in literature, and this analysis do not provide conclusive evidence of a linear relationship between flue gas temperature and $\mathrm{NO}_{\mathrm{x}}$ emissions.

- $\quad \mathrm{NO}_{\mathrm{x}}$ emissions and $\mathrm{SO}_{2}$ emissions: Pearson and Spearman rank correlation indicate medium to very strong positive correlation between $\mathrm{NO}_{x}$ and $\mathrm{SO}_{2}$ emissions across batches. Also, a distinct relationship between $\mathrm{NO}_{x}$ and $\mathrm{SO}_{2}$ emissions have not been established in literature, a medium to very strong positive correlation suggests a linear relationship between the release of $\mathrm{NO}_{\mathrm{x}}$ and $\mathrm{SO}_{2}$ emissions. This may be attributed to higher temperature leading to higher release of $\mathrm{NO}_{\mathrm{x}}$ and $\mathrm{SO}_{2}$ emissions.

- Flue gas velocity and Flue gas temperature: Pearson and Spearman rank correlation indicate very poor to strong positive and negative correlation between flue gas velocity and temperature, suggesting that the relationship between these two metrics is either non-linear or non-existent. 
Table 3: Pearson and Spearman rank correlation evaluating the relationships between emission metrics across batch 2 to batch 13

\begin{tabular}{|c|c|c|c|c|c|c|c|c|c|c|c|c|c|c|c|c|c|c|}
\hline \multirow{2}{*}{$\begin{array}{c}\text { Batch } \\
\text { Correlation }\end{array}$} & \multicolumn{2}{|c|}{2} & \multicolumn{2}{|c|}{3} & \multicolumn{2}{|c|}{4} & \multicolumn{2}{|c|}{8} & \multicolumn{2}{|c|}{9} & \multicolumn{2}{|c|}{10} & \multicolumn{2}{|c|}{11} & \multicolumn{2}{|c|}{12} & \multicolumn{2}{|c|}{13} \\
\hline & $P$ & $S$ & $P$ & S & $P$ & S & $P$ & $S$ & $P$ & $S$ & $P$ & S & $P$ & S & $P$ & S & $P$ & $S$ \\
\hline $\begin{array}{c}\mathrm{CO} / \\
\text { Temperature }\end{array}$ & -0.30 & -0.18 & -0.29 & -0.15 & -0.40 & -0.21 & -0.50 & -0.39 & -0.36 & -0.39 & -0.33 & -0.16 & -0.31 & -0.16 & 0.01 & 0.18 & -0.37 & -0.15 \\
\hline $\begin{array}{c}\mathrm{SO}_{2} \mathrm{I} \\
\text { Temperature }\end{array}$ & 0.82 & 0.77 & 0.53 & 0.77 & 0.63 & 0.71 & 0.42 & 0.52 & 0.49 & 0.58 & 0.12 & 0.12 & 0.62 & 0.77 & 0.55 & 0.48 & ND & ND \\
\hline $\mathrm{NOx} / \mathrm{SO}_{2}$ & 0.83 & 0.39 & 0.63 & 0.43 & 0.41 & 0.35 & 0.66 & 0.72 & 0.72 & 0.67 & 0.93 & 0.90 & 0.66 & 0.59 & 0.43 & 0.70 & ND & ND \\
\hline $\begin{array}{c}\text { NOx I } \\
\text { Temperature }\end{array}$ & 0.63 & 0.39 & 0.23 & 0.30 & 0.13 & 0.22 & -0.06 & -0.01 & 0.13 & 0.17 & 0.02 & 0.07 & 0.26 & 0.30 & 0.05 & 0.15 & 0.04 & 0.01 \\
\hline $\begin{array}{c}\text { Velocity I } \\
\text { Temperature }\end{array}$ & -0.60 & -0.62 & -0.24 & -0.26 & 0.17 & 0.12 & 0.15 & 0.15 & 0.15 & 0.17 & 0.07 & 0.03 & 0.16 & 0.20 & -0.26 & -0.24 & -0.03 & 0.01 \\
\hline
\end{tabular}

NOTE: Correlation is classified as "Very weak" $=0.0-0.19$; "Weak" $=0.20-0.39$; "Medium" $=0.40-0.59$; "Strong" $=0.60-0.79$; "Very strong" $=0.80-0.99$

$P$ refers to Pearson correlation, S refers to Spearman Rank correlation and ND means "no data"

Batch 5,6 and 7 data are not included due to discrepancies in data analysis.

\subsection{Relationship between Fuel Input Parameters and Emission Metrics}

Several fuel input parameters were analysed in order to determine their relationships with emission metrics. Correlation analysis was conducted using both Pearson and Spearman rank correlation to evaluate the relationships between fuel input parameters (these include total sulfur, percentage total carbon, percentage total volatiles, percentage total ash); and atmospheric emissions (including $\mathrm{CO}, \mathrm{NO}_{2}, \mathrm{NO}_{x}$ and $\mathrm{SO}_{2}$ emission factors). Significant relationships are discussed below, while correlation results are shown in Table 4:

- A strong positive correlation is observed between total ash content in external fuel and PM emissions, indicating that higher ash content in external fuel yields higher PM emissions. No distinct relationship is observed between percentage ash content in internal fuel and PM emissions.

- A strong negative correlation was observed between sulfur content in internal fuel and $\mathrm{SO}_{2}$ emissions, suggesting a reduction in release of $\mathrm{SO}_{2}$ emission when internal sulfur content is high. This indicates that more sulfur is captured within the brick with higher internal sulfur content and may be attributed to the complex reaction that occurs within the bricks, causing retention (rather than release) of sulfur in the bricks as $\mathrm{CaSO}_{4}$ (Akinshipe \& Kornelius, 2017a).

- A strong positive correlation was also observed between carbon content (both internal and external fuels) and CO emissions, indicating that higher carbon content in the fuel yield higher CO emissions, which is indicates inefficient combustion.

- A strong positive correlation was also observed between volatile compounds in external fuels and CO emissions, indicating that higher volatile compounds in the fuel also yield higher $\mathrm{CO}$ emissions. This also indicates inefficient combustion.

- $\quad$ Finally, a strong positive correlation was also observed between the following: volatile compounds in external fuel and $\mathrm{SO}_{2}$ emissions; total carbon in external fuel and $\mathrm{SO}_{2}$ emissions etc.

Table 4: Correlation analysis evaluating the relationships between fuel input parameters and emission metrics across batch 2 to batch 13

\begin{tabular}{|c|c|c|c|c|c|c|c|c|}
\hline \multirow{2}{*}{ Emission Metrics } & \multicolumn{4}{|c|}{ Pearson Correlation } & \multicolumn{4}{c|}{ Spearman Rank Correlation } \\
\cline { 2 - 9 } Fuel Input Parameters & $\mathbf{C O}$ & $\mathbf{N O}$ & $\mathbf{N O}$ & $\mathbf{S O}_{2}$ & $\mathbf{C O}$ & $\mathbf{N O}_{\mathbf{x}}$ & $\mathbf{N O}$ & $\mathbf{S O}_{2}$ \\
\hline total sulfur (internal fuel) & -0.22 & 0.12 & 0.12 & -0.69 & -0.48 & 0.19 & 0.19 & -0.77 \\
\hline total sulfur (external fuel) & -0.10 & -0.23 & -0.23 & 0.20 & 0.17 & -0.22 & -0.22 & 0.35 \\
\hline total carbon (internal fuel) & -0.19 & -0.01 & -0.01 & -0.02 & -0.22 & 0.06 & 0.06 & -0.22 \\
\hline total carbon (external fuel) & 0.32 & -0.17 & -0.17 & 0.58 & 0.70 & 0.06 & 0.06 & 0.69 \\
\hline volatile compounds (internal fuel) & -0.35 & 0.25 & 0.25 & -0.13 & -0.62 & 0.24 & 0.24 & -0.31 \\
\hline volatile compounds (external fuel) & 0.28 & -0.29 & -0.29 & 0.63 & 0.75 & -0.11 & -0.11 & 0.62 \\
\hline total ash (internal fuel) & -0.02 & -0.19 & -0.19 & -0.12 & -0.05 & 0.07 & 0.07 & 0.05 \\
\hline total ash (external fuel) & 0.32 & -0.41 & -0.41 & 0.14 & 0.33 & -0.30 & -0.30 & -0.07 \\
\hline
\end{tabular}

NOTE: Correlation is classified as "Very weak" $=0.0-0.19$; "Weak" $=0.20-0.39$; "Medium" $=0.40-0.59$; "Strong" $=0.60-0.79$; "Very strong" $=0.80-0.99$

\section{Conclusions and Recommendations}

The model kiln design has proven to be adequate in firing bricks. It also proved effective in capturing and channelling emissions from a simulated clamp kiln in order for adequate monitoring to be taken; a quest which has met with limited success until now. It has been shown that measured model kiln emissions and firing process metrics exhibit high emissions inconsistency during each firing 
cycle, denoting the sensitivity of the emission to various chemical reactions and thermodynamic processes that occurs within the pseudo-firing chamber of the kiln at a particular period. These concentrations and process metrics exhibit little or no similarity across firing campaigns; which may be attributed to the significantly varying input, packing and firing conditions applied to each batch. A high standard deviation, as well as high data spread across the batches, indicates that emissions and process metrics from the kiln are sensitive to these input and firing variables. All pollutant emission rates and emission factors were successfully quantified (except for $\mathrm{NO}_{2}$ emissions). Significant $\mathrm{NO}_{2}$ is not emitted from a clamp kiln, since all of the $\mathrm{NO}_{\mathrm{x}}$ emitted is actually released in the form of NO. It was also shown that a similarity in $\mathrm{PM}_{1}, \mathrm{PM}_{2.5}, \mathrm{PM}_{4}, \mathrm{PM}_{10}$ and $\mathrm{PM}_{15}$ emission factors exists, which indicate that combustion PM is composed of extremely fine PM (since it is made up of nucleotides and particles that are yet to coagulate in the atmosphere).

In addition, it is expected that use of an energy alternative (such as liquidified petroleum gas, propane gas or diesel) will improve clamp kiln firing efficiency and consequently result in reduction of atmospheric emissions, since the external fuel has been shown to be most sensitive to emission metrics. A significant reduction of 0.8 to $0.9 \mathrm{MJ} / \mathrm{kg}(32 \%-36 \%)$ indicates that the industry could still achieve significant reduction in energy use, thereby potentially reducing cost of energy input, and also, significantly reducing the quantity of atmospheric emissions. Based on this potential reduction in energy use, 27528 tons of $\mathrm{CO}$ emission, 171 tons of NO emission, 0 ton of $\mathrm{NO}_{2}$ emission, 1310 tons of $\mathrm{SO}_{2}$ emission, 463174 tons of $\mathrm{CO}_{2}$ emission and 1873 tons of hydrocarbons emission were quantified as potential annual reduction in South African clamp kilns.

The following are measures that clamp kiln operators can adopt to reduce quantity of emissions: crushing, screening, milling and mixing of clay material and other additives is adequate to achieve homogeneity - homogeneity during processing and mixing of material is required to ensure that the constituents of clay and fuel material are evenly distributed across the firing batch; monitoring of kiln temperature by distributing thermocouples within the kiln and ensure a steady rise or fall in temperature; utilization of clay and coal materials that contain lower sulfur, carbon and metal contents; reduction of coal use by reducing current specific energy consumption as feasible as possible (closer to $2.5 \mathrm{MJ} / \mathrm{kg}$ ) without compromising the firing process; as well as ensuring adequate sun drying of bricks prior to firing to help reduce energy consumption required for water-smoking or slow heating of the firing process.

The novelty of this research is in the design of the clamp kiln structure and simulation of the firing process which enables capture, confinement and channelling of flue gases to a point where representative measurement are obtained. In addition, computational analyses are utilized to generate representative emission rates and emission factors, as well as energy metrics that have hitherto proven infeasible.

In conclusion, the model kiln design and simulation technique adopted for quantifying emissions from clamp kilns could be utilized in further study for similar complex configuration sources.

\section{Supplementary Material}

Additional data are provided in Supplementary material.

\section{Acknowledgments}

The project was hosted by Nova Bricks (Pty) Ltd. The Clay Brick Association of South Africa funded part of the study and its members were generous with their time, products and site amenities. The financial assistance of the National Research Foundation (NRF) towards this research is hereby acknowledged. Opinions expressed and conclusions arrived at, are those of the author and are not necessarily to be attributed to the NRF.

\section{References}

Ahmad, M., Leon, J., Shah, H., Masood, T., Büker, P., Emberson, L., Ashmore, M., 2011. Hydrogen fluoride damage to vegetation from peri-urban brick kilns in Asia: A growing but unrecognised problem? Environ. Pollut. 162, 319-324. doi:10.1016/j.envpol.2011.11.017

Akinshipe, O., 2013. The development of an "emission inventory tool" for brick making clamp kilns, M.Sc. thesis, University of Pretoria.

Akinshipe, O., Kornelius, G., 2017a. The quantification of atmospheric emissions from complex configuration sources using reverse dispersion modelling. Int. J. Environ. Sci. Technol. 14, 2367-2378. doi:10.1007/s13762-017-1316-0

Akinshipe, O., Kornelius, G., 2017b. Chemical and Thermodynamic Processes in Clay Brick Firing Technologies and Associated Atmospheric Emissions Metrics - A Review. J Pollut Eff Cont 5. doi:10.4176/2375-4397.1000190

Akinshipe, O., Kornelius, G., 2016. Provisional Findings of Atmospheric Emissions From Clamp Kilns In The South African Clay Brick Industry, in: Clean Air Conference. National Association for Clean Air.

Akinshipe, O., Kornelius, G., 2015. Atmospheric Emissions from Clamp Kilns in The South African Clay Brick Industry, in: Clean Air Conference. National Association for Clean Air, Bloemfontein, South Africa.

Assadi, A., Abdollah, G., Fatemeh, M., Nasrin, T., Leila, A., 2011. Impact of air pollution on physiological and morphological characteristics of Eucalyptus camaldulensis. J. Food Agric. Environ. 9, 676-679. 
Bartok, W., Sarofim, A., 1991. Fossil Fuel Combustion: A Source Book. Wiley-Interscience, John Wiley \& Sons.

Biarnes, M., Freed, B., Esteves, J., 2013. Combustion, Technical booklet, E Instruments Inc.

Brosnan, D., Sanders, J., 2005. Residual sulfur in clay bricks - investigations on North American products. Ziegelindustrie Int 10, $25-31$.

Brownell, W.E., 1960. Retention of sulfates by fired clay products. J Am Ceram Soc 43, 179-183. doi:10.1111/j.11512916.1960.tb12978.x

Brownell, W.E., 1949. Fundamental factors influencing efflorescence of clay products. J Am Ceram Soc 32, 375-389. doi:10.1111/j.1151-2916.1949.tb18917.x

Burger, L., Breitenbach, N., 2008. Air Quality Impact Assessment of Apollo Bricks Atlantis Manufacturing Facility (Brakkefontein): Proposed Dryer and Tunnel Kiln Process. Airshed Planning Professionals (Pty) Ltd, Technical Report, Airshed Planning Professionals (Pty) Ltd. Midrand, South Africa.

Cardenas, B., Bouwman, H., Costner, P., Fiedler, H., Grochowalsky, A., Mirikau, C., Thanner, G., Umlauf, G., 2009. Unintentional released POPs from brick production in developing countries, Technical report, Joint Research Commission, European Commission.

CBA, 2015. Clay Brick Technical Guide, Clay Brick Association Technical Guide. Midrand, South Africa.

CBA, 2005. The making of clay bricks, Clay Brick Association. Clay Brick Association, South Africa.

CBA, 2002. Technical brochure on how to specify or build with clay brick, CBA technical guide. Midrand, South Africa.

Croitoru, L., Sarraf, M., 2012. Benefits and Costs of the Informal Sector: The Case of Brick Kilns in Bangladesh. J. Environ. Prot. (Irvine,. Calif). 3, 476-484. doi:10.4236/jep.2012.36058

Cultronea, G., Sebastiána, E., Elerta, K., de la Torreb, M., Cazallaa, O., Rodriguez-Navarroa, C., 2003. Influence of mineralogy and firing temperature on the porosity of bricks. J. Eur. Ceram. Soc. 24, 547-564. doi:10.1016/S0955-2219(03)00249-8

Darain, K.M., Jumaat, M.Z., Islam, A.B.M., Obaydullah, M., Iqbal, A., Adham, M.I., Rahman, M.M., 2016. Energy efficient brick kilns for sustainable environment. Desalin. Water Treat. 57.

Daraina, K.M., Rahmanb, A., Ahsanc, A., Islamd, A., Yusuf, B., 2013. Brick Manufacturing Practice in Bangladesh: of Energy Efficacy and Air Pollution Scenarios" Journal of Hydrology and Environment Research, Vol No 1. 1 SRC-G.

DEA, 2010. Modelling Case Study of Section 21 Emission Standards for Industrial Sources in the Highveld Priority Area, Technical Report, Department of Environmental Affairs. Pretoria, SA.

E Instruments, 2008. E5500 Portable Industrial Integrated Emissions System Combustion Gas Analyzer-, Instruction and Operations Manual, E Instruments International LLC. Langhorne, USA.

Ferdausi, S.A., Vaideeswaran, S., Akbar, S., 2008. Green brick making industries in Bangladesh, in: Better Air Quality Conference. Bangkok, Thailand.

Gredmaier, L., Banks, C., Pearce, R., 2011. Calcium and sulphur distribution in fired clay brick in the presence of a black reduction core using micro X-ray fluorescence mapping. Constr. Build. Mater. 25, 4477-4486. doi:10.1016/j.conbuildmat.2011.03.054

Grim, R.E., Johns, W.D., 1951. Reactions Accompanying the Firing of Brick. J Am Ceram Soc 34, 71-76. doi:10.1111/j.11512916.1951.tb13487.x

Guttikunda, S.K., Begum, B.A., Wadud, Z., 2013. Particulate pollution from brick kiln clusters in the Greater Dhaka region, Bangladesh. Air Qual. Atmos. Heal. 6, 357-365. doi:10.1007/s11869-012-0187-2

Guttikunda, S.K., Khaliquzzaman, M., 2014. Health benefits of adapting cleaner brick manufacturing technologies in Dhaka, Bangladesh. Air Qual Atmos Heal. 7 SRC-G, 103-112. doi:doi.org/10.1007/s11869-012-0187-2

Haack, B., Khatiwada, G., 2007. Rice and Bricks: Environmental Issues and Mapping of the Unusual Crop Rotation Pattern in the Kathmandu Valley, Nepal. Env. Manag. 39, 774-782. doi:10.1007/s00267-006-0167-0

Hashemi, A., Cruickshank, H., 2015. Embodied Energy of Fired Bricks: The Case of Uganda and Tanzania, in: 14th International Conference on Sustainable Energy Technologies. Nottingham, England.

Heywood, J., 1988. Internal Combustion Engine Fundamentals. McGraw-Hill, New York.

Irm, F., 2011. Impact of brick kiln emissions on the ambient air quality and vegetation-A case study of district Budgam. MPhil Thesis. University of Kashmir, Srinagar.

Klepetsanis, P., Dalas, E., Koutsoukos, P., 1999. Role of temperature in the spontaneous precipitation of calcium sulfate dihydrate" Langmuir, . 15, 1534-1540.

Lalchandani, D., 2012. Zigzag Kilns - Public Policies to reduce environmental impact of artisanal brick production, Greentech Knowledge Solutions. Guanajuato, Mexico.

Lordan, P., 2011. Technology Transfer mechanism - Introduction of Vertical Shaft Brick Kiln (VSBK) Technology at Vhavenda Brick, South Africa, in: Clean Development Mechanism, Project Design Document Form. South Africa. 
Maithel, S., Lalchandani, D., Malhotra, G., Bhanware, P., Rajarathnam, U., Ragavan, S., Athalye, V., Bindiya KR, Reddy, S., Bond, T., Weyant, C., Baum, E., Thoa, V.T.K., Phuong, N.T., Thanh TK, 2012. Monitoring of brick kilns strategies for cleaner brick production in India, Shakti Sustainable Energy and Climate Works Foundation. India.

Pariyar, S., Das, T., Ferdous, T., 2013. Environment and Health Impact For Brick Kilns In Kathmandu Valley. Int. J. Sci. Technol. Res. 2.

Pokhrel, R., Lee, H., 2014. Integrated Environment Impact Assessment of Brick Kiln using Environmental Performance Scores. Asian J. Atmos. Environ. 8, 15-24. doi:10.5572/ajae.2014.8.1.015

Rajasthan State Pollution Control Board, 2012. Guidelines for Abatement of Pollution in Brick Kiln Industry, Administrative Staff College Report. Jaipur, India.

Rajasthan State Pollution Control Board, 2011. Environmental guidance manual: Brick kilns, Administrative Staff College Report. India.

Raut, A., 2003. Brick Kilns in Kathmandu Valley: Current and Future Options. Him J Sci. 1, 59-61.

Ross, S., 2014. Introduction to probability and statistics for engineers and scientists, 5th ed. Elsevier Inc., San Diego, USA.

Rowden, E., 1964. The firing of Bricks. Thomas Forman \& Sons Ltd, Nottingham, England.

Skinder, B., Pandit, A., Sheikh, A., Ganai, B., 2014. Brick kilns: Cause of Atmospheric Pollution. J Pollut Eff Cont 2. doi:10.4172/2375-4397.1000112

Umlauf, G., Bouwman, H., Cardenas, B., Fiedler, H., Mariani, G., Mirikau, C., Skejo, H., Thanner, G., 2011. PCDD/F, PCB and HCB in soil and ash from brick production sites in Kenya, South Africa and Mexico. Organohalogen Compd. 73, 1041-1045.

USEPA, 1999. Nitrogen Oxides (NOx), Why and How They Are Controlled, Technical Report, Clean Air Technology Center, US Environmental Protection Agency. North Carolina, USA.

USEPA, 1997. Section 11.3 Brick and Structural Clay Products, Emission Factor Documentation for AP-42, United States Environmental Protection Agency. North Carolina, USA.

Vent-Axia, 2015. Bifurcated Case Axial Fans (BIFA), Catalogue, Vent-Axia. West Sussex, UK.

Vent-Axia, 2010. Bifurcated Axial Fan - Installation and Wiring Instructions, Technical Instructions, Vent-Axia.

World Bank, 1998. Greenhouse Gas Assessment Handbook: A practical guidance document for the assessment of project-level greenhouse gas emissions, Global Environment Division Report. New York, USA.

World Bank, 1997. Urban Air Quality Management Strategy in Asia (URBAIR), Kathmandu Valley Report. New York, USA. 